\title{
TÉCNICOS ADMINISTRATIVOS E POLÍTICAS AFIRMATIVAS: O OUE MUDOU NA UNIVERSIDADE ESTADUAL DE FEIRA DE SANTANA
}

\author{
Administrative technicians and affirmative policies: \\ what has changed at Feira de Santana State University
}

Wildacy Gonçalves Ribeiro Evangelista

Cintia Souza Machado Ferreira

\section{RESUMO}

Este estudo, amparado em pesquisa bibliográfica e documental, discorre sobre a implantação de Políticas Públicas de Ações Afirmativas na Universidade Estadual de Feira de Santana (UEFS) e os impactos na rotina laboral dos Técnicos Administrativos da instituição. Tem como objetivo verificar os efeitos causados à categoria com a extinção de uma Unidade de Organização e Desenvolvimento Comunitário, cuja finalidade era o desenvolvimento de ações direcionadas à qualidade de vida e o bem-estar social de Técnicos, Docentes e Discentes, para implantação de uma Pró-Reitoria de Políticas Afirmativas e Assuntos Estudantis voltada aos estudantes. Os resultados apontam para a necessidade de uma melhor compreensão das políticas de ações afirmativas por toda a Comunidade Universitária, evidencia as mudanças que acometeram os Técnicos Administrativos em detrimento dessa modificação organizacional, revela a exiguidade de capacitação sistêmica para atendimento, apoio e suporte à população cotista e sinaliza a necessidade de um olhar atento da UEFS às reivindicações dos Técnicos Administrativos por melhoria nas condições de trabalho e qualidade de vida.

Palavras-Chave: Técnicos administrativos. Políticas afirmativas. Mudança organizacional. UNDEC. PROPAAE. 


\section{ABSTRACT}

This study, supported by bibliographical and documentary research, discusses the implementation of Public Policies for Affirmative Actions at the State University of Feira de Santana (UEFS) and the impacts on the work routine of the institution's Administrative Technicians. It aims to verify the impact of the extinction of an Organization and Community Development Unit to the category, whose purpose was the development of actions aimed at life quality and social well-being of Technicians, Teachers and Students, for the implantation of a Pro-Dean of Affir- mative Policies and Student Affairs aimed at students. The results point to the need for a better understanding of affirmative action policies across the University Community, showing the changes that have affected Administrative Technicians in detriment of this organizational change, reveal the lack of systemic training to support the quota population, and signal the need for a close look to Administrative Technicians demands for improving working conditions and life quality by UEFS.

Keywords: Administrative technicians. Affirmative policies. Organizational change. UNDEC. PROPAAE.

A institucionalização de Políticas Públicas de Ações Afirmativas na Universidade Estadual de Feira de Santana (UEFS), autarquia pertencente ao Governo do Estado da Bahia, teve como marco a adoção do sistema de reserva de vagas, a partir do semestre 2007.1, para grupos historicamente excluídos do acesso à educação superior - estudantes da escola pública, negros e não negros, indígenas e quilombolas.

Até o semestre anterior a implantação do sistema de cotas na Universidade contava com ações pontuais de assistência e permanência (bolsa alimentação, bolsa auxílio e residência universitária) já que a população estudantil era composta, em maioria, por estudantes oriundos das classes mais privilegiadas da sociedade.

As ações de assistência estudantil demandadas eram de responsabilidade da Unidade de Organização e Desenvolvimento Comunitário (UNDEC), órgão de assessoramento à Administração Superior cuja missão era "desenvolver e implementar políticas, programas e ações de integração e valorização dos servidores(as) técnico administrativos, professores(as) e estudantes" (UEFS, 2011); para cumprir a sua missão, possuía diversificadas atribuições e ofertava variados serviços.

Com a ampliação dos cursos de graduação, adoção das ações afirmativas e, consequentemente, aumento da população cotista, a UEFS vislum- 
brou a criação de uma unidade com a finalidade específica de promover as políticas afirmativas, o que ocorreu em 2014 com a instalação da Pró-Reitoria de Políticas Afirmativas e Assuntos Estudantis (PROPAAE), momento em que ocorreu a desativação da UNDEC, o direcionamento de atribuições e serviços passou para outras unidades da Universidade, dentre eles todos os oferecidos aos Técnicos Administrativos.

Com base nesse cenário, foi possível elaborar a questão norteadora: os serviços oferecidos pela UNDEC aos Técnicos Administrativos como ações de assistência e distribuídos para outras unidades da Universidade continuaram sendo ofertados? Amparado em pesquisa documental e em dados secundários da UEFS, o artigo tem como objetivo identificar os impactos para os Técnicos Administrativos com a extinção da referida unidade.

A justificativa para a elaboração do artigo, em consonância com a temática "Direitos humanos e políticas públicas", é de trazer a discussão para os serviços assistenciais oferecidos à categoria dos Técnicos Administrativos da UEFS no âmbito da Universidade, e que eram ofertados pela extinta UNDEC, onde podem ser acessados, se foram modificados, ampliados, reduzidos ou, ainda, extintos.

\section{DA EXTINÇÃO DA UNDEC À CRIAÇÃO DA PROPAAE: POR QUE MUDAR?}

A expansão da UEFS ocasionada pelo aumento do número de cursos de graduação e pós-graduação lato sensu e stricto sensu, a necessidade de ampliar e democratizar o acesso à Universidade para grupos historicamente excluídos da educação superior, a introdução do sistema de cotas e o estabelecimento de Políticas Públicas de Ações Afirmativas na instituição foram fatores responsáveis por alterações no organograma da Universidade de modo a comportar um novo cenário composto por uma população maior, mais diversa e heterogênea.

Até então a UNDEC atendia a demandas dos servidores Técnicos Administrativos, professores e estudantes, "estabelecendo políticas e diretrizes no intuito de integrar e possibilitar a promoção social da Comunidade Universitária” (UEFS, 2011). Atuava com os três seguimentos da comunidade universitária e para isso contava com alguns setores.

A Divisão de Ação Comunitária (DIAC) tinha sob a sua supervisão duas coordenações: Coordenação de Integração Comunitária (CICOM) e Coordenação de Assuntos Estudantis (CODAE), buscava viabilizar atividades para a 
integração, melhoria das relações interpessoais e socioculturais e a valorização da Comunidade Universitária. Por meio da CICOM, desenvolvia atividades que englobavam as três categorias (servidores técnico-administrativos, docentes e estudantes) e da CODAE voltava-se para a assistência ao estudante.

Alguns convênios eram firmados entre a UEFS e Entidades extracampus por meio da CICOM, a fim de oferecer serviços odontológicos, lazer e programas específicos voltados sempre para o bem-estar e para a melhoria da qualidade de vida dos Técnicos Administrativos, docentes e seus dependentes, como a Assessoria Jurídica que oferecia serviços jurídicos gratuitos para a comunidade universitária nas mais diversas varas e juizados. Na CICOM também se concentravam os serviços de fiscalização dos contratos das Cantinas e do Restaurante Universitário.

A assistência estudantil ficava a cargo da CODAE, esta trabalhava diretamente com o apoio logístico para participação discente em eventos científicos, a Residência Universitária que abrigava estudantes com vulnerabilidade socioeconômica oriundos de outras cidades, os Programas de estágios institucionais curriculares não obrigatórios (Bolsa Estágio Acadêmico e Bolsa Auxílio Especial), a atuação como balcão de estágios criando parcerias com os agentes de integração e empresas previamente conveniadas pela UEFS e, ainda, com o apoio de outros setores da universidade, em que prestava assistência técnica e financeira às atividades de cunho artístico-culturais apresentadas pelos Diretórios Acadêmicos (DAs), Diretório Central dos Estudantes (DCE), Núcleos e Empresas Juniores. A partir de 2007 a CODAE passou a trabalhar também com o Sistema Bandejão para oferta, no Restaurante Universitário (RU), de subsídios integral e parcial a estudantes regularmente matriculados na graduação e na pós-graduação por meio da Bolsa Alimentação.

O Serviço de Apoio Psicopedagógico (SAP) oferecia atendimento aos estudantes de forma geral, porém mais especificamente aos estudantes residentes e o Serviço Social atuava acolhendo as demandas e direcionando as três categorias acadêmicas, quando necessário, ao Serviço Social, Serviço de Saúde Universitário (SESU) ou para atendimento na rede municipal de apoio, além de realizar avaliações socioeconômicas para acessos aos programas institucionais. O SESU, serviço de atenção primária a saúde, era destinado à comunidade universitária e disponibilizava atendimento médico (clínica geral), odontológico, psicológico, enfermagem, nutrição e serviço social, e ainda dispunha do Programa de Prevenção e Intervenção em Doenças Cardiovasculares: fatores de risco (PPIDCV). 
Sob a supervisão da UNDEC também ficava o Centro de Educação Básica da UEFS (CEB/Creche e Escola). A Creche atendendo aos filhos de servidores da UEFS na faixa etária de 4 meses a 6 anos em turnos que os pais estariam trabalhando. E a Escola, fruto de convênio entre a UEFS e Prefeitura Municipal de Feira de Santana, atendendo a crianças de toda a comunidade de Feira de Santana na faixa etária de 7 a 15 anos, que para ingressar participavam de sorteio eletrônico. Outro setor sob a gestão da UNDEC era a Livraria Interuniversitária que fazia parte do Programa Interuniversitário para Distribuição do Livro (PIDL) e que ainda hoje é membro da Associação Brasileira de Editoras Universitárias (ABEU).

Por muitos anos a UNDEC cumpriu seu papel de integrar e valorizar servidores e estudantes, promovendo atividades e criando políticas para a disseminação do conhecimento, o bem-estar social e o desenvolvimento institucional.

A partir dos anos 80 começam a eclodir na sociedade brasileira questões sobre a necessidade de se implantar políticas de ações afirmativas de reparação histórica para com negros e indígenas, porém a partir de 2001, depois da Conferência de Durban, na África do Sul ${ }^{1}$, a questão racial passou a ser olhada sob uma ótica a ser encarada pela sociedade brasileira. Em 2003, o então Presidente Luis Inácio Lula da Silva criou a Secretaria Especial de Políticas de Promoção da Igualdade Racial (SEPPIR) e em 2004 encaminhou ao Congresso Nacional projeto de lei propondo o estabelecimento de um "sistema especial de reserva de vagas para estudantes egressos de escolas públicas, em especial negros e indígenas, nas instituições públicas federais de ensino superior" (BRASIL, 2004). Após um longo período de discussões, somente em 2012, o projeto foi deliberado com a publicação da Lei de Cotas.

A conhecida política de cotas para ingresso nas universidades tornou-se assunto principal em vários debates e muitos se colocaram contrários, mas por todo país, ativistas, professores e estudantes se movimentaram para que essa política de ação afirmativa fosse efetivada. Na UEFS não ocorreu diferente e em 2006, sob forte pressão do Núcleo de Estudantes Negros e Negras da UEFS (NENNUEFS), ocorreu a implantação do sistema de cotas.

1 II Conferência Mundial contra o Racismo, Discriminação Racial, Xenofobia e Intolerância Correlata realizada em 2001 na cidade de Durban, África do Sul. 
A partir de então se intensificaram na Universidade as discussões sobre ações que pudessem dar conta dos estudantes ingressantes a partir do semestre 2007.1 e todas as suas dificuldades para permanecer na universidade até a conclusão do curso de graduação. Surgiu daí a necessidade de se criar um setor que pudesse abarcar políticas voltadas para as ações afirmativas e a assistência estudantil. Iniciou-se, então, a demanda pela criação de uma Pró Reitoria que tratasse prioritariamente de questões estudantis, até porque apenas a CODAE não conseguiria atender a todas as demandas advindas desse processo.

Em 2012, assumiu como Chefe da UNDEC o Professor Otto Vinícius Agra Figueiredo com a missão de realizar as mudanças necessárias para a instalação da Pró Reitoria de Políticas Afirmativas e Assuntos Estudantis (PROPAAE) da qual seria seu primeiro Pró-Reitor, o que ocorreu em outubro de 2014. A função de Chefe da UNDEC, antes exercida por um Técnico Administrativo, passou a ser ocupada por um Docente e assim segue, visto que o Regimento da PROPAAE estabelece que o Pró-Reitor será um Docente do quadro efetivo da UEFS.

Entre os anos de 2012 a 2014 os serviços realizados na UNDEC direcionados aos Técnicos Administrativos e Docentes foram transferidos para outras unidades da UEFS ou foram extintos, conforme relacionado a seguir.

Os convênios que ofereciam serviços voltados para o bem-estar e a qualidade de vida dos servidores foram extintos assim como o Serviço de Assessoria Jurídica (SAJ) que deixou de atender aos servidores e passou a coordenação do Curso de Direito, para que as aulas práticas fossem ministradas aos estudantes, hoje atende a pessoas de baixa renda que procuram acesso à justiça. Atualmente os referidos serviços são ofertados pelo Sindicato dos Trabalhadores em Educação do $3^{\circ}$ Grau do Estado da Bahia (SINTEST).

O SAP e o Serviço Social passaram a atender predominantemente a estudantes até 2018 quando, houve a contratação (por meio de Concurso Público) de uma Assistente Social para a Pró-Reitoria de Gestão e Desenvolvimento de Pessoas (PGDP), após um rápido período de transição, o atendimento ao estudante passou a ser exclusivo. O SESU passou para a supervisão da Reitoria com todos os seus serviços, assim como o CEB/Escola. O CEB/Creche passou a ser acompanhado pela PGDP e a Livraria Universitária passou a integrar a Editora UEFS que se reporta diretamente a Reitoria. 
No processo de desativação da UNDEC, a PROPAAE foi se estruturando para atender as demandas por ações afirmativas e assistência estudantil, com a missão de:

1. Propor, planejar e acompanhar as Políticas de Ações Afirmativas no âmbito da Universidade Estadual de Feira de Santana visando atender a comunidade universitária.

2. Planejar, implementar, coordenar, e consolidar Programas de Assistência Estudantil que visem ampliar condições para a permanência, prioritariamente, para as (os) estudantes de graduação em situação de vulnerabilidade social e/ ou integrante de comunidades tradicionais historicamente excluídos do ensino superior com vistas a contribuir para a promoção social pela educação.

3. Planejar, implementar, coordenar, e consolidar as ações de apoio aos estudantes e às entidades estudantis. (PROPAAE, 2017).

O Organograma da PROPAAE apresenta a seguinte estrutura: Pró-Reitor, Coordenação Geral, Secretaria, Coordenações e Núcleos. A Coordenação Geral atua diretamente com as coordenações e núcleos no intuito de acompanhar, subsidiar e supervisionar os trabalhos por estes desenvolvidos. A Secretaria assessora toda a pró-reitoria. A Coordenação de Políticas Afirmativas (CPAFIR) tem como principal atribuição "propor, orientar, avaliar, acompanhar e divulgar as Políticas e Programas de Ações Afirmativas" (PROPAAE, 2017), mas também tem um papel fundamental na articulação para o fortalecimento dessas políticas.

A Coordenação de Assuntos Estudantis (CODAE) permaneceu com todas as atribuições anteriores, mas sob limitações impostas pelo Governo do Estado com o contingenciamento dos gastos públicos a partir de novembro de 2015, a UEFS suspendeu o apoio logístico para participação discente em eventos científicos e apoio financeiro às atividades artístico-culturais apresentadas pelos DAs, DCE, Núcleos e Empresas Juniores. Toda a fiscalização do contrato e acompanhamento sistêmico quanto ao RU ficou sob a responsabilidade do Núcleo de Alimentação no Campus (NAC), assim como o contrato das Cantinas.

O Núcleo de Apoio Psicossocial e Pedagógico (NAPP) surgiu da junção entre o SAP e o Serviço Social, que juntos formaram o Núcleo de Apoio 
Psicossocial e Pedagógico com o objetivo de orientar, assessorar, organizar e acompanhar ações que possibilitem a promoção e o aperfeiçoamento do processo de ensino-aprendizagem, com apoio social, psicológico e pedagógico aos estudantes. Para acesso ao Programa de Assistência Estudantil (PAE), o estudante passa por avaliação socioeconômica realizada por este Núcleo.

A instalação da PROPAAE foi fundamental para os discentes da UEFS que conquistaram um espaço onde todas as demandas e problemas advindos das ações afirmativas e da assistência estudantil pudessem ser avaliadas, discutidas e encaminhadas na busca por soluções, representando para a Universidade um significativo passo na consolidação institucional de Políticas Públicas Afirmativas. Para os Técnicos Administrativos, entretanto, houve impactos significativos a partir do momento em que as ações para melhoria das condições de trabalho e de qualidade de vida foram pulverizadas para diversos setores.

A instalação da PGDP, pró-reitoria voltada para os servidores, só ocorreu dois anos após a instalação da PROPAAE, em 2016, e resultou da reorganização da Gerência de Recursos Humanos (GRH) ligada até então à Pró-Reitoria de Administração (PROAD). A expectativa era de que com a PGDP ocorresse uma assistência mais efetiva à categoria, porém as mais diversas e complexas demandas com Servidores (Técnicos e Docentes), associadas à implantação do sistema RH Bahia pelo Governo do Estado e todos os problemas advindos dele, não permitiu, até aqui, que essa pró-reitoria desenvolvesse ações específicas e mais significativas para os Técnicos Administrativos.

\section{AÇÕES AFIRMATIVAS NA UEFS: O SERVIDOR TËCNICO ADMINISTRATIVO NOS PROCESSOS DE IMPLANTAÇÃO E EXECUÇÃO DE POLÍTICAS PÚBLICAS AFIRMATIVAS}

As ações afirmativas são medidas utilizadas para promover a igualdade de grupos historicamente excluídos em detrimento da raça, gênero, deficiência ou de orientação sexual ou ainda em situação de vulnerabilidade socioeconômica e inseri-los em espaços anteriormente não ocupados (mercado de trabalho, representação política e universidades) promovendo o processo de inclusão social, de redução das desigualdades e de transformação da realidade de vida destes indivíduos. Para Figueiredo (2019, p. 178),

Ações afirmativas são compreendidas como medidas ou políticas de caráter público ou privado que objetivam pro- 
TÉCNICOS ADMINISTRATIVOS E POLITICAS AFIRMATIVAS:

O QUE MUDOU NA UNIVERSIDADE ESTADUAL DE FEIRA DE SANTANA

mover a justiça social através de ações específicas para determinados grupos sociais e/ou étnico-raciais com histórico de discriminação e exclusão.

$\mathrm{Na}$ área educacional as ações afirmativas são concebidas como políticas públicas de promoção do acesso, assistência e permanência dos estudantes em todos os níveis da educação e nas universidades públicas se concretizaram com a publicação da Lei no 12.711, de 29 de agosto de 2012 (Lei de Cotas), que instituiu a reserva de vagas nos cursos de graduação para grupos historicamente excluídos do acesso à educação superior (negros, indígenas, quilombolas) ou com renda familiar inferior a 1,5 salário mínimo, (BRASIL, 2012).

Para Nunes e Novais (2014, p. 92-93),

É preciso pensar as políticas públicas de educação como práticas culturais, como representações sociais e históricas que servirão aos diferentes grupos sociais. Por isso, é importante observar e ressaltar que essas políticas não são inócuas e têm destinatários. Sendo assim, as políticas públicas educacionais para a classe popular deverão ser pensadas com a finalidade de promover a inclusão, a aprendizagem e a conclusão dos estudos, de modo qualificado.

Na UEFS, a implantação de políticas de ações afirmativas se deu antes da determinação federal, culminou com a instituição do sistema de reserva de vagas, por meio da Resolução CONSU no 034 de 20 de julho de 2006, com o estabelecimento de cotas sociais e étnico raciais para candidatos negros, não negros oriundos de escola pública, indígenas e quilombolas, (UEFS, 2006).

Em 2020, ao completar 44 anos de existência e treze anos da implantação do sistema de cotas, é possível asseverar que a UEFS democratizou e expandiu o acesso à educação superior ao desenvolver importantes ações dentro da sua Política Afirmativa:

implantação de bolsas, de uma Residência Universitária e de um Restaurante Universitário (Sistema Bandejão) como ações de assistência e permanência estudantil;

criação de uma Pró-Reitoria com a finalidade específica de propor e acompanhar a política pública desenvolvida na Universidade; 
constituição de uma Câmara de Políticas Afirmativas e Assuntos Estudantis com o objetivo de submeter e apreciar normas para as Ações Afirmativas institucionais;

fundação de uma Residência Universitária exclusiva para estudantes indígenas, sendo a primeira Universidade no Estado da Bahia a promover tão importante feito, garantindo a estes estudantes a manutenção da sua cultura;

oferecimento de uma turma exclusiva do Curso de Bacharelado em Direito para estudantes do Programa Nacional da Reforma Agrária (PRONERA), em convênio com o Instituto Nacional de Colonização e Reforma Agrária (INCRA) - turma concluída em 2018. Uma nova turma, também para este público específico, já foi autorizada nas instâncias internas da UEFS, mas a Universidade aguarda a autorização do Governo Federal para o início das atividades acadêmicas suspensas desde o ano de 2019 em todo o território nacional, quando ocorreu a extinção da Coordenação da Educação do Campo por meio do Decreto $n^{\circ} 10.252$, de 20 de fevereiro de 2020 (BRASIL, 2020), publicado pelo Governo Jair Bolsonaro, desconsiderando uma política pública já estabelecida de acesso à educação superior.

instituição de um Programa de Assistência Estudantil (PAE) unificando todas as ações de assistência e permanência da Universidade (auxílios, restaurante universitário, residências universitárias, apoio aos estudantes - psicossocial, pedagógico, clínico, ambulatorial, apoio às ações culturais, desportivas e recreativas e as entidades estudantis).

Os Técnicos Administrativos das Universidades do Estado da Bahia (UEBAs), aqui incluída a UEFS, cujas carreiras foram criadas pela Lei $\mathrm{n}^{\circ}$ $\underline{8.889}$, de $1^{\circ}$ de dezembro de 2003 (BAHIA 2003), e reestruturadas pela Lei $n^{\circ}$ $11.375_{z}$ de 05 de fevereiro de 2009, estão divididos em duas categorias: os Analistas Universitários "profissionais de nível superior responsáveis pelas atividades de suporte técnico aos projetos e ações administrativas e acadêmicas executados nas Universidades Estaduais" e os Técnicos Universitários "profissionais com o ensino médio ou técnico responsáveis pelas atividades de suporte técnico de média complexidade aos projetos e ações operacionais, administrativas e acadêmicas das Universidades Estaduais”, com vencimentos e planos de carreiras específicos para cada categoria (BAHIA, 2009). 
A UEFS, há algum tempo, atravessa significativa redução no quadro de Técnicos Administrativos em virtude de exonerações, aposentadorias e movimentações de servidores para outras universidades ou outros órgãos pertencentes a estrutura do Estado da Bahia, e não preenche essas vagas pela não realização de concursos públicos em decorrência de contingenciamento da máquina pública promovido pelo Governo Estadual. A vivência das autoras enquanto servidoras Técnicas Administrativas, pertencentes à carreira de Analista Universitário, permite afirmar que, mesmo contando com um quantitativo de servidores abaixo do previsto na legislação que reestruturou as carreiras dos Técnicos Administrativos das UEBAs, existe um comprometimento de parte considerável dos servidores da UEFS na propositura e realização de ações que aperfeiçoem a prestação de serviços à Comunidade Universitária (Interna e Externa), dinamizem os fluxos de processos e assegurem a estruturação de inéditas políticas públicas na Universidade.

Na UEFS, é responsabilidade dos Pró-Reitores, Assessores Especiais e Chefes de Unidades auxiliar a Reitoria no planejamento e execução das diversas atividades universitárias (acadêmicas e administrativas), além da elaboração de políticas públicas destinadas à Comunidade Universitária e o seu entorno. Conforme informação disponível no site institucional, dos dezenove cargos que compõe a atual gestão da Universidade, período 20192023, apenas sete são ocupados por Técnicos Administrativos pertencentes ao quadro funcional da Universidade, os demais são ocupados por Docentes e Servidores Comissionados sem vínculo efetivo com a instituição e por Servidores de outros órgãos à disposição da UEFS. Apesar da maioria dos Técnicos Administrativos possuir qualificação acima da requerida para desempenho de suas atividades, conforme tabela 1, são preteridos para ocupação de cargos pertencentes ao primeiro escalão da Universidade e consequentemente dos processos de construção de políticas públicas.

TABELA 1: TITULAÇÃO DOS TÉCNICOS ADMINISTRATIVOS DA UEFS

\begin{tabular}{c|c|c|c|c|c}
\hline $\begin{array}{c}\text { Técnicos } \\
\text { Administrativos }\end{array}$ & $\begin{array}{c}\text { Ensino } \\
\text { Médio }\end{array}$ & Graduados & Especialistas & Mestres & Doutores \\
\hline Analistas & 00 & 32 & 109 & 76 & 20 \\
\hline Técnicos & 172 & 120 & 35 & 04 & 00 \\
\hline
\end{tabular}

FONTE: Gerência de Recursos Humanos/Subgerência de Admissão e Acompanhamento de Pessoas (GRH/SAAP): 2019. 
A PROPAAE, unidade responsável pelas políticas afirmativas, possui em sua equipe Técnicos Administrativos pertencentes as duas categorias de servidores e dentre os Analistas Universitários encontram-se Assistentes Sociais, Pedagogos e Psicólogos, inseridos nas subunidades da Pró-Reitoria, para atendimento aos estudantes da instituição, preferencialmente os cotistas, mas, tanto os Analistas Universitários, independentemente de suas formações, quanto os Técnicos Universitários executam suas atividades/ atribuições/tarefas buscando a efetividade da missão da pró-reitoria.

É tácita a importância dos Técnicos Administrativos da UEFS nos processos de implantação e execução de Políticas Afirmativas, assim como a participação nas atividades que permitiram a inserção da Universidade no rol das instituições públicas de ensino superior do Brasil que, mesmo com as constantes reduções nos orçamentos e consequente comprometimento das ações de assistência e permanência aos estudantes beneficiários do sistema de cotas, não mediram esforços para promover a expansão e a democratização do acesso ao ensino superior. Esse esforço, que ora atribuiu-se a UEFS, não seria possível sem os Técnicos Administrativos a quem cabe a missão de desenvolver as ações rotineiras, técnicas, quase sempre invisíveis, e que tantas vezes, mesmo não participando dos processos decisórios, apresentam projetos, ideias, sugestões, planos e novas formas de administrar e gerir a máquina pública, assim como ampliar e melhorar os programas afirmativos da Universidade.-

Aqui se pode exemplificar a criação do Programa de Assistência Estudantil da UEFS, construído a várias mãos, especialmente pelas servidoras técnicas da PROPAAE e com representação dos docentes, discentes e entidades sindicais da Universidade. Sem os Técnicos Administrativos para a execução de tarefas práticas (cumprimento de etapas, adequação à legislação já existente nas esferas estadual e federal, ajustamento do programa à realidade da Universidade e de sua população cotista) a proposta não teria chegado às instâncias superiores para aprovação, logo pode-se afirmar que são os Técnicos Administrativos um dos pilares fundamentais e imprescindíveis para o sucesso das políticas afirmativas e da permanência estudantil na Universidade.

Os técnicos administrativos na UEFS são contemplados pelas seguintes políticas afirmativas: ingresso de novos servidores à Universidade, por meio de Concurso Público, em cumprimento ao Estatuto da Igualdade Racial e de Combate à Intolerância Religiosa do Estado da Bahia - Lei 
Estadual $n^{\circ} 13.182$, de 06 de junho de 2014, que instituiu a reserva mínima de $30 \%$ (trinta por cento) das vagas para a população negra nos concursos públicos e processos seletivos (BAHIA 2014), e utilização do nome social quando o nome oficial não refletir a sua identidade de gênero nos espaços da instituição, conforme Resolução CONSEPE $n^{\circ} 15$, de 23 de março de 2015 (UEFS, 2015). Em 2017, por meio do Decreto Estadual no 17.523, de 23 de março de 2017 (BAHIA, 2017), ficou estabelecido o uso do nome social e o reconhecimento da identidade de gênero no âmbito da administração pública estadual.

A atenção, cuidado e zelo com os Técnicos Administrativos da UEFS é premente. O Restaurante Universitário (RU), inaugurado em 2007, sob a fiscalização da UNDEC, atendia aos estudantes subsidiados, com cotas integrais para os residentes e cotas parciais para os demais estudantes de graduação e pós-graduação na modalidade de bandejão, mas também atendia a servidores técnicos e docentes na modalidade de self service, para isso o espaço físico era dividido e as rampas eram separadas para que se pudesse servir ambas as modalidades.

Em 11 de abril de 2012, um grupo de estudantes autodenominado "rapinagem" ocupou o restaurante e de lá saíram quase cinco meses depois, no dia 03 de setembro, impondo algumas condições, dentre elas a ampliação do espaço com uma única modalidade de serviço para toda a comunidade universitária. O RU foi reaberto no dia 12 de setembro de 2013, um ano depois, e funciona até os dias atuais sob a modalidade bandejão atendendo prioritariamente a estudantes subsidiados pela universidade em horários específicos e com fila única. Qualquer pessoa da comunidade universitária e visitantes também podem realizar as refeições (café, almoço ou jantar) no "bandejão" pagando o valor integral das refeições.

Realizar as refeições na UEFS permitiria aos Técnicos Administrativos conforto e comodidade já que a Universidade está localizada fora do centro urbano da cidade de Feira de Santana; os servidores que trabalham 40 horas não necessitariam se locomover até as suas residências ou até o centro da cidade e os que trabalham 30 horas poderiam realizar o café da manhã ou jantar nos intervalos de suas jornadas. Os Técnicos Administrativos, assim como os docentes e visitantes, podem utilizar o Restaurante Universitário no sistema bandejão, como já foi dito, mas se deparam com longas filas que se formam para acesso ao local, o que demanda tempo para utilização do serviço e o comprometimento da jornada de trabalho. Há oito anos os 
Técnicos Administrativos cobram, sem sucesso, a Administração Superior da UEFS o retorno do serviço em separado para a categoria.

Neste processo de construção e institucionalização de Políticas Afirmativas na UEFS, tão importante quanto se pensar a inclusão dos Técnicos Administrativos é capacitar a categoria para o desenvolvimento das atividades que envolvem o sistema de cotas na Universidade. Para além da mudança ocorrida com a desativação da UNDEC e a criação da PROPAAE, pode-se notar também que os técnicos não foram treinados e ou preparados para receber as políticas de ações afirmativas e com isso muitos não sabem como lidar com elas. É preciso um conhecimento que considere a diversidade humana em todas as suas nuances, e muitas vezes a falta deste traz comportamentos de estranheza e intolerância. Entender quem são os indivíduos, de onde vieram, qual a sua cultura, que dificuldades enfrentaram, de que forma chegaram e o que querem para o futuro é de fundamental importância para que se dê um atendimento adequado, mais humano e livre de pré-conceitos.

São inúmeras as situações que causam desconforto nessa relação Técnicos Administrativos e Estudantes Cotistas, muito em torno da ausência de habilidades técnicas e emocionais, competências que podem ser desenvolvidas com ações específicas desencadeadas, na UEFS, pela PGDP e a PROPAAE. O constrangimento no atendimento aos estudantes deficientes, homossexuais e trans, os conceitos pré-existentes sobre os estereótipos indígenas e quilombolas, a ausência de empatia com os que reivindicam uma política de assistência estudantil mais ampla e justa, com os que cobram o pagamento dos auxílios, com os que apresentam um rendimento acadêmico insatisfatório são exemplos das nuances dessa delicada relação, acarretando para os Técnicos Administrativos situações diárias de estresse e incapacidade no cumprimento de suas tarefas.

Os embates rotineiros e o acúmulo de situações problemas envolvendo Técnicos e Cotistas podem ser evitados com uma postura proativa da Universidade. Elaborar Políticas Afirmativas vai além do estabelecimento de um sistema de cotas para grupos historicamente excluídos do acesso ao ensino superior, pois a efetividade dessa política não ocorrerá se a permanência material e simbólica não contemplar os estudantes partícipes do sistema de cotas. As relações conflituosas vividas na Universidade fazem com que muitos destes estudantes não se sintam pertencentes a instituição, comprometendo assim a permanência simbólica. 
TÉCNICOS ADMINISTRATIVOS E POLÍTICAS AFIRMATIVAS:

O OUE MUDOU NA UNIVERSIDADE ESTADUAL DE FEIRA DE SANTANA

\section{CONSIDERAÇÕES FINAIS}

O sucesso das Políticas de Ações Afirmativas na UEFS só se dará de forma efetiva quando houver uma compreensão geral de sua necessidade e importância por parte toda a comunidade universitária e de modo especial, pela administração superior, por todos os setores e por parte dos Técnicos Administrativos.

A PGDP oferece alguns treinamentos, mas estes abordam temas mais específicos e técnicos como SEI, RH Bahia, Licitação e alguns outros. A PROPAAE em uma ação pontual, enxergando a dificuldade em todos os setores da UEFS para lidar com alguns estudantes, ofereceu um curso sobre ações afirmativas para Técnicos Administrativos, mas não houve apoio institucional, visto que alguns chefes não liberaram os funcionários para participação no curso. Em 2019, a PROPAAE e a PGDP tentaram mais uma vez oferecer o curso e não obtiveram sucesso, não houve adesão. A PGDP ofereceu no último concurso uma capacitação para conhecimento geral da instituição, mas este não discutiu questões sobre ações afirmativas.

Fica claro a necessidade de articulação institucional entre a pró-reitoria específica, a PGDP e demais setores administrativos no sentido de possibilitar ações conjuntas para sensibilização e informação da comunidade universitária (técnicos, docentes e estudantes) sobre as ações afirmativas e as suas particularidades.

A Política de Ações Afirmativas é parte das políticas públicas para reparação das desigualdades e o combate ao racismo e é de extrema importância, porém, por não conseguir conciliar os diversos interesses em jogo, a Universidade tem favorecido um grupo específico em detrimento de outro, não atentando para as necessidades dos Técnicos Administrativos em meio à adoção da mencionada política, e assim leva inclusive a resistência de muitos servidores em aceitar e dialogar sobre as ações afirmativas.

A UEFS precisa voltar o olhar aos servidores da instituição, visto que as demandas apresentadas por estes têm uma grande importância no aspecto motivador do desempenho de suas atividades e na redução das situações de estresse vivenciadas diariamente por estes.

Faz-se necessário então, dedicar-se a criação de cursos de capacitação e ou formação sobre as ações afirmativas que contemplem funcionários de vários setores, criação de projetos de extensão para estimular a melhor convivência entre técnicos e estudantes, realização de atividades físicas e culturais voltadas para o bem-estar dos servidores, suporte psicológico, 
constituição de comissão de ética para resolução de problemas institucionais sem a necessidade de abertura de Processos Administrativos Disciplinares, direcionamento do atendimento jurídico do curso de direito também aos servidores e a reabertura do Restaurante Self-Service.

Somente construindo um atendimento não desigual para estudantes e Técnicos Administrativos as ações afirmativas se tornarão sólidas e cumprirão um papel de combate ao racismo e o não fortalecimento das desigualdades sócio raciais. O conjunto destas ações citadas implicariam numa convivência mais tranquila, produtiva e eficaz para todos os membros da Comunidade Universitária.

\section{REFERÊNCIAS}

BAHIA. Decreto $\mathbf{n}^{\mathbf{0}} \mathbf{1 7 . 5 2 3}$, de 23 de março de 2017. Dispõe sobre o uso do nome social e o reconhecimento da identidade de gênero de pessoas travestis e transexuais no âmbito da Administração Pública Estadual direta, autárquica e fundacional. Disponível em: <http://www.legislabahia.ba.gov. br/documentos/decreto-no-17523-de-23-de-marco-de-2017>. Acesso em: 10 jul. 2020.

BAHIA. Lei $\mathrm{n}^{\circ} \mathbf{8 . 8 8 9}$, de 01 de dezembro de 2003. Dispõe sobre a estrutura dos cargos e vencimentos no âmbito do Poder Executivo do Estado da Bahia e dá outras providências. Disponível em: <http://www. portaldoservidor.ba.gov.br/grupos-ocupacionais-carreiras>. Acesso em: 29 jun. 2020.

BAHIA. Lei $\mathrm{n}^{\circ} \mathbf{1 1 . 3 7 5}$, de 05 de fevereiro de 2009. Reestrutura as carreiras de Analista Universitário e Técnico Universitário, integrantes do Grupo Ocupacional Técnico-Específico, criado pela Lei no 8.889, de 01 de dezembro de 2003, bem como o seu padrão remuneratório, e dá outras providências. Disponível em: <http://www.legislabahia.ba.gov.br/ documentos/lei-no-11375-de-05-de-fevereiro-de-2009>. Acesso em: 29 jun. 2020.

BAHIA. Lei ${ }^{\circ}$ 13.182, de 06 de junho de 2014. Institui o Estatuto da Igualdade Racial e de Combate à Intolerância Religiosa do Estado da Bahia e dá outras providências. Disponível em: <http://www.mpsp.mp.br/portal/ page/portal/GT_Igualdade_Racial/Outros/Lei\%2013.182\%2006.06.14\%20 Bahia.pdf>. Acesso em: 26 jun. 2020.

BRASIL. Decreto $\mathrm{n}^{\mathbf{0}} \mathbf{1 0 . 2 5 2}$, de 20 de fevereiro de 2020. Aprova a Estrutura Regimental e o Quadro Demonstrativo dos Cargos em Comissão e das Funções de Confiança do Instituto Nacional de Colonização e Reforma Agrária - Incra, e remaneja cargos em comissão e funções de 
TÉCNICOS ADMINISTRATIVOS E POLITICAS AFIRMATIVAS:

O QUE MUDOU NA UNIVERSIDADE ESTADUAL DE FEIRA DE SANTANA

confiança. Disponível em: <http://www.in.gov.br/web/dou/-/decreto-n10.252-de-20-de-fevereiro-de-2020-244585036>. Acesso em: 30 jun. 2020.

BRASIL. Lei $\mathbf{n}^{\circ} \mathbf{1 2 . 7 1 1}$, de 29 de agosto de 2012. Dispõe sobre o ingresso nas universidades federais e nas instituições federais de ensino técnico de nível médio. Disponível em: <www.planalto.gov.br/ccivil_03/_ato20112014/2012/lei/112711>. Acesso em: 09 jul. 2020.

BRASIL. Projeto de lei $\mathbf{n}^{\mathbf{0}} \mathbf{3 . 6 2 7}$, de 20 de maio de 2004. Institui Sistema Especial de Reserva de Vagas para estudantes egressos de escolas públicas, em especial negros e indígenas, nas instituições públicas federais de educação superior e dá outras providências. Disponível em: $<$ http://portal. mec.gov.br/arquivos/pdf/ref_projlei3627.pdf>. Acesso em: 30 de jun. de 2020.

FIGUEIREDO, O. V. A. Acesso de indígenas e quilombolas na Universidade Estadual de Feira de Santana - UEFS. Cadernos do Lepaarq, v. XVI, n. 31, p. 176-191, jan./jun., 2019.

NOVAIS, G. S.; NUNES, S. do C. Políticas públicas educacionais: a educação básica entre o prescrito e o real. Rev. Ed. Popular, Uberlândia, v. 13, n. 2, p. 81-93, jul./dez. 2014. Disponível em: <http://www.seer.ufu. br/index.php/reveducpop/article/view/28627/15921>. Acesso em 10 jun. 2020 .

UNIVERSIDADE ESTADUAL DE FEIRA DE SANTANA. Resolução CONSU $n^{\circ}$ 34, de 20 de julho de 2006. Estabelece a reserva de vagas para os cursos de graduação da UEFS, para grupos historicamente excluídos, realizada através do Processo Seletivo de Acesso ao Ensino Superior. Feira de Santana: UEFS, 2006.

UNIVERSIDADE ESTADUAL DE FEIRA DE SANTANA. Resolução CONSEPE $\mathbf{n}^{\circ} \mathbf{1 5}$, de 23 de março de 2015. Dispõe sobre o tratamento nominal das pessoas transexuais e travestis na Universidade Estadual de Feira de Santana e dá providências correlatas. Feira de Santana: UEFS, 2015.

UNIVERSIDADE ESTADUAL DE FEIRA DE SANTANA. Missão da PROPAAE. Feira de Santana: UEFS. Disponível em: <http://www. propaae.uefs.br $/$ modules $/$ conteudo $/$ conteudo.php? conteudo $=2>$.

Acesso em: 02 jul. 2020.

UNIVERSIDADE ESTADUAL DE FEIRA DE SANTANA. A UNDEC. Feira de Santana: UEFS. Disponível em: <http://www2.uefs.br:8081/ estagio_undec/>. Acesso em: 26 jun. 2020. 